sprinting capacity. This implicates that introducing eccentric hamstring strengthening during pre/early season seems relevant as this may both increase sprinting performance and mitigate the risk of $\mathrm{HI}$ during the in-season.

\section{HIGH CONCUSSION RATE AMONGST SOUTH AFRICAN UNIVERSITY RUGBY STUDENT TOURNAMENT}

1,2James Craig Brown, 1,2 Lindsay Starling, ${ }^{3,4}$ Keith Stokes, 1,2 Pierre Viviers, ${ }^{1,2,7}$ Sean Surmon, ${ }^{1,2}$ Keith Derman. 'Institute of Sport and Exercise Medicine, Division of Orthopaedics, Department of Surgical Sciences, Stellenbosch University, Cape Town, South Africa; ${ }^{2}$ IOC Research Centre, South Africa, Cape Town, South Africa; ${ }^{3}$ Department for Health, University of Bath, Bath, UK; ${ }^{4}$ Rugby Football Union, London, UK; ${ }^{7}$ Maties Sport, Stellenbosch University, Stellenbosch, South Africa

\subsection{6/bjsports-2021-IOC. 149}

Background Of all injuries common to collision sports, concussions have received the most attention due to the potentially negative cognitive effects in the short- and long- term. Stellenbosch Rugby Football Club ('Maties'), the official rugby club of Stellenbosch University, represents one of the world's largest non-professional Rugby clubs, making this an ideal cohort for community level injury surveillance.

Objective To describe the incidence and events associated with concussion in this large non-professional homogenous cohort.

Design A one-season prospective cohort injury surveillance study.

Setting Students (young adults) athletes competing in the internal ('Koshuis') tournament of the Maties Rugby Club in 2018

Patients (or Participants) All 807 male players registered for the Koshuis tournament in 2018, which was comprised of 101 matches and 2,915 of exposure hours. The average age, height and weight of this cohort was $20 \pm 2$ years, $182 \pm 7 \mathrm{~cm}$ and $88 \pm 14 \mathrm{~kg}$, respectively.

Interventions (or Assessment of Risk Factors) Recording of all injuries, and factors associated with injury, according to the consensus statement for injury recording in rugby.

Main Outcome Measurements Overall, there were 89 timeloss injuries, which equated to an injury rate of 31 per 1000 match hours $(95 \%$ confidence intervals [CIs]: 2437 ), or about one injury per match. The most common injury diagnosis was 'concussion' ( $\mathrm{n}=27$ out of 90 injuries, $30 \%)$, at a rate of 9 per 1000 match hours $(95 \%$ CIs: 6-12).

Results The three most common mechanisms of concussion in the present study were performing a tackle (33\%), accidental collision (30\%) and being tackled (11\%).

Conclusions Concussion was the most common injury in this population, at a rate that was six times higher than a comparable cohort in the UK. Future studies should try to explain this higher rate and subsequently reduce these concussions.

\section{3 GENDER DIFFERENCES IN HEAD IMPACT RATE AND MECHANISM IN HIGH SCHOOL LACROSSE}

'Declan Patton, 1,2Colin Huber, 1,3Valerie Lallo, 1,4Catherine McDonald, ${ }^{1,5}$ Kristy Arbogast. ${ }^{1}$ Center for Injury Research and Prevention, Children's Hospital of Philadelphia, Philadelphia, $P A$, USA; ${ }^{2}$ Department of Bioengineering, University of Pennsylvania, Philadelphia, PA, USA; ${ }^{3}$ Department of Biomedical Engineering, Widener University, Chester, PA, USA; ${ }^{4}$ School of Nursing, University of Pennsylvania, Philadelphia, PA, USA; ${ }^{5}$ Perelman School of Medicine, University of Pennsylvania, Philadelphia, PA, USA

\subsection{6/bjsports-2021-IOC.150}

Background There is debate as to whether protective headwear should be mandated in female lacrosse; however, a lack of quantitative evidence exists regarding the effectiveness of, and case for, protective headwear in female lacrosse.

Objective To compare head impacts in male and female lacrosse in terms of rate recorded by headband-mounted sensors and mechanism determined by video analysis.

Design Prospective observational study.

Setting One season of suburban high school female (12 games) and male (15 games) lacrosse competition.

Participants Adolescent female $(n=15)$ and male $(n=33)$ lacrosse players.

Main Outcome Measurements Head impact rate as calculated by the number of video-confirmed head impacts above $16 \mathrm{~g}$ recorded by SIM-G (Triax Technologies) headband-mounted impact sensors divided by the number of player-games during one season. Mechanism of impact (i.e. player contact, fall, stick-to-head or ball-to-head) determined by detailed video analysis of sensor-recorded events.

Results For male lacrosse, 226 head impacts were recorded during 272 player-games for an impact rate of 0.83 impacts per player-game. The most common mechanism for head impacts to male lacrosse players was player contact $(57 \%)$ followed by stick-to-head (27\%), falls (15\%) and ball-to-head (2\%). For female lacrosse, 7 head impacts were recording during 109 player-games for an impact rate of 0.06 impacts per player-game. Of the seven head impacts to female lacrosse players, three were player contact $(43 \%)$, three were stick-tohead $(43 \%)$ and one was a fall (14\%).

Conclusions The impact rate for female lacrosse players is less than $8 \%$ of the rate for male lacrosse players, which suggests that head impacts in female high school lacrosse are rare. However, nearly half of the head impacts in female lacrosse were stick-to-head, for which protective headwear may reduce the risk of injury. Therefore, further investigation of the association between head impact mechanism and injury in female lacrosse is required.

\section{NORMATIVE BASELINE SCAT5 SCORES IN A POPULATION OF UNITED STATES OLYMPIC ATHLETES}

${ }^{1,5}$ Lauren Pierpoint, ${ }^{2,5}$ Laura Zdziarski, ${ }^{3,5}$ David Taylor, ${ }^{4}$ William Moreau, ${ }^{3,5}$ Dustin Nabhan.
'Steadman Philippon Research Institute, Vail, USA; ${ }^{2}$ University of Utah, Department of
Orthopaedics, Salt Lake City, USA; ${ }^{3}$ USA Olympic and Paralympic Committee, Colorado
Springs, USA; ${ }^{4}$ Southern California University of Health Sciences, Whittier, USA; ${ }^{5}$ USA
Coalition for the Prevention of IIIness and Injury in Sport, Colorado Springs, USA

10.1136/bjsports-2021-IOC.151

Background The Sport Concussion Assessment Tool $5^{\text {th }}$ Edition (SCAT5) is the most recent version of the concussion 